it seems pertinent to ask if the debris in the fault planes may not represent crevasse fillings. This would explain the absence of fine material in the fillings, as fines are frequently winnowed out of morainal material that has been on the ice surface for some time.

It should also be noted that the fault planes shown in Souchez' figure 3 have dips that are rather steep to be accounted for by normal shear deformation, and that offset of the foliation, as shown, is in the wrong direction to be attributed to such shear. Interpreting these features as crevasse fillings might be more consistent with the observations at hand.

Finally, Weertman's objection to the shear hypothesis is based on the fact that fault-type shear displacements across infinitely thin planes $(\mathrm{d} V / \mathrm{d} y \rightarrow \infty)$ probably do not occur commonly in ice under high hydrostatic pressure as at the base of an ice sheet. Plastic deformation with finite shear strain ( $\mathrm{d} V / \mathrm{d} y$ finite) is probably the normal mode of flow. Used in this latter sense, the term "shear moraine" is valid. However Bishop (1957, p. 17) refers to debris being carried to the surface along "high-angle imbricate shears". This implies a fracture or fault type of displacement and the term shear moraine thus has a very explicit genetic connotation. For this reason it seems desirable to abandon the term. I have used the name "ice-perched moraine" in my Greenland work.

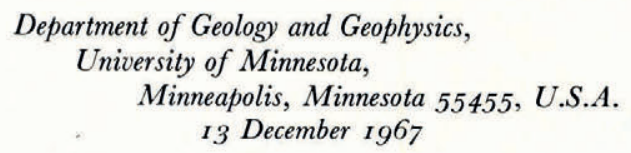

Roger LeB. HoOKe

\title{
REFERENCES
}

Bishop, B. C. 1957. Shear moraines in the Thule area, northwest Greenland. U.S. Snow, Ice and Permafrost Research Establishment. Research Report i 7.

Souchez, R. A. 1967. The formation of shear moraines: an example from south Victoria Land, Antarctica. Fournal of Glaciology, Vol. 6, No. 48, p. 837-43.

\section{SIR, Reply to Dr R. LeB. Hooke's comments on "The formation of shear moraines: an example from south Victoria Land, Antarctica"}

In his comments on my paper (Souchez, 1967 ), Hooke poses three questions: the first is merely for information about the causes of upwarping and the possible occurrence of a wind-drift ice wedge; the second deals with an alternative explanation of the localized fault planes filled with debris and considered as crevasse fillings; and the last is a problem of terminology about the well-known term "shear moraine".

First, in contrast to the north-west Greenland situation described by Hooke, the role of wind-drift ice wedges is, to my mind, not applicable in the case studied. In the Upper Ferrar Glacier area, at an altitude of $\mathrm{r} 800 \mathrm{~m}$, melting is exceptional and only localized near rock outcrops. Superimposed ice is not significant. Ice formation is a very slow process which occurs mainly by pressure of the overlying snow without the participation of surface melt water. This reduces the possibility of wind-drift ice wedges in this area. On the other hand, if we refer to figure 2 of my paper (Souchez, 1967) and if we assume that the first (northern) and oldest morainic ridge in region "C" was formed at the boundary between glacier ice and a wind-drift ice wedge, it is difficult to explain in a similar manner the second ridge, and the third which is even less developed. Everywhere between the ridges there is the same blue dense ice which is characteristic of Upper Ferrar Glacier. It should also be noted that the ridges in region "C" are not parallel to the boundary and that, when it is not masked by debris, the base of the ice shows foliation bands, dirt bands and debris bands dipping up-glacier, a situation not easily explained by a wind-drift ice wedge. That wind-drift ice wedges may play an important role in the genesis of some socalled "shear moraines" is very probable. Østrem (1964) has emphasized the role of old snow banks in the formation of ice-cored moraines in Scandinavia. But we must also take into account, in other cases, that upwarping may be caused by a stagnant wedge of glacier ice having slow plastic deformation and no basal sliding, because of the presence of permafrost beneath the glacier which extends inwards some distance from its edge. Finally, because of my participation in a programme on southern Ellesmere Island with the Geological Survey of Canada, I saw so-called "shear moraines" not too far from Thule. Even there, the upwarping cannot always be attributed to the process mentioned by Hooke. Some 
"ice-perched morainic ridges" are oblique, even perpendicular to the ice-cap margin and their petrographical composition indicates very clearly a subglacial origin in a region where there are no nunataks. This study will soon be ready for publication.

Secondly, Hooke asks pertinently if the interpretation of the localized debris-containing fault planes as crevasse fillings is not more consistent with the field observations. He attributes the absence of fines $(<6 \mathrm{~mm})$ in the deposit to the fact that they are frequently winnowed out of morainal material that has been on the ice surface for some time. Open crevasses are rare in Upper Ferrar Glacier and when they exist they are surprisingly clean. The climatic environment has a strong influence by preventing the carrying and concentration action of melt water. Furthermore, supraglacial morainic material travelling on the ice is very infrequent and it consists of blocks and slabs, while gravels are abundant in the localized debris-containing fault planes. Concerning the removal of fines, as water is absent, wind is the only agent able to do that. The katabatic wind can indeed be strong in the area, but it is difficult to understand why its action of removal of fines should be restricted to this kind of deposit alone and have no effect on the other nearby morainic deposits. One can answer that wind action need not necessarily have occurred in the area itself. However, the area is only $10 \mathrm{~km}$ from the last nunataks and the great ice sheet of eastern Antarctica. On the other hand, a petrographic study of the debris in the fault planes indicates a local origin. All these facts seem to reduce the possibility of numerous crevasse fillings in this area.

Concerning the offset of the foliation in my figure 3 , I agree with Hooke's observation. Even if the situation represented in cross-section appears locally, it would have been preferable to suggest in the figure the opposite offset which is the normal one.

Finally, concerning terminology and the use of the term "shear moraine", we have to consider separately the respective situations at the base of an ice sheet under high hydrostatic pressure and at its margin.

In my paper, I justified the use of this expression and the fact that the Weertman hypothesis cannot explain the whole situation described. On the other hand, the term "shear moraine" (moraine de cisaillement) is an old expression, first introduced in 1904 as Lliboutry (1964-65) says, so that the historical aspect of the question should be known before any decision is taken either to preserve or replace the term.

The term "ice-perched moraine" is interesting but what would be the difference between it and "ice-cored moraine"?

Service de Géomorphologie,

R. A. Sovchez

Université Libre de Bruxelles, Bruxelles 5, Belgium

27 December 1967

\section{REFERENCES}

Lliboutry, L. 1964-65. Traité de glaciologie. Paris, Masson et Cie. 2 vols.

Østrem, G. I964. Ice-cored moraines in Scandinavia. Geografiska Annaler, Vol. 46, No. 3, p. $282-337$.

Souchez, R. A. 1967. The formation of shear moraines: an example from south Victoria Land, Antarctica. fournal of Glaciology, Vol. 6, No. 48, p. 837-43.

SIR, Glaciological observations in north-central Greenland

During early July 1966 we were fortunate in being able to visit "Inge Lehman" station, a camp established by the Arctic Institute of North America and the U.S. Air Force, on the Greenland ice sheet. Our purpose was to test small-scale traverse techniques using Bombardier "Ski-doos" and to make snow studies south-east of the station in an area hitherto unstudied. We also intended, if possible, to locate "Northice", the 1952-54 ice-sheet station of the British North Greenland Expedition, and obtain snow accumulation and deformation measurements. Because of changes in flight schedules, the traverse to the south-east, which was intended to be approximately $160 \mathrm{~km}$ in length, had to be shortened to $28 \mathrm{~km}$. "Northice" was revisited and a series of measurements were made. Figure I shows "Northice" on 4 July 1966 and can be compared with Banks ( $\left.{ }^{c}{ }^{1} 957\right]$, p. 128$)$ and Simpson (1957, p. 2 1 3,220$)$. The following are the results of the measurements: 